\title{
Study on Extraction of Sodium Alginate from Kelp by Method of Calcium Coagulation-Ion Exchange
}

\author{
Jinling Gao*, Shuting Zhao
}

Collage of Science, Heilongjiang Bayi Agricultural University, Daqing, China

DOI: $\underline{10.36347 / \text { sjavs.2020.v07i02.002 }}$

| Received: 05.02.2020 | Accepted: 13.02.2020 | Published: 16.02.2020

*Corresponding author: Jinling Gao

Abstract

Original Research Article

In this study, the effects of concentration of $\mathrm{Na}_{2} \mathrm{CO}_{3}$, time of digestion, and temperature of digestion on the extraction rate of sodium alginate by calcium coagulation-ion exchange were investigated by single factor test and orthogonal test using commercially available kelp as raw materials. Results show that concentration of $\mathrm{Na}_{2} \mathrm{CO}_{3}$ effects on extraction yield of sodium alginate is of high significance, temperature of digestion and time of digestion have less effect on the extraction yield of sodium alginate. The best experiment condition is obtained by the analysis of the orthogonal experiment results, when concentration of $\mathrm{Na}_{2} \mathrm{CO}_{3}$ is $8 \%$, digestion time is $3 \mathrm{~h}$, and temperature of digestion is $50^{\circ} \mathrm{C}$, the highest extraction yield of sodium alginate is achieved. The viscosity of sodium alginate solution was $131 \mathrm{~Pa} \cdot \mathrm{s}^{-1}\left(20^{\circ} \mathrm{C}\right)$ in the product.

Keywords: Kelp; Sodium alginate; Calcium coagulation-ion exchange method; Orthogonal experiment; Extraction.

Copyright @ 2020: This is an open-access article distributed under the terms of the Creative Commons Attribution license which permits unrestricted use, distribution, and reproduction in any medium for non-commercial use (NonCommercial, or CC-BY-NC) provided the original author and source are credited.

\section{INTRODUCTION}

Sodium alginate is a natural polysaccharide, it is mainly extracted from kelp or sargasso. Because it has the stability, solubility, viscosity and safety required by the excipients of pharmaceutical. Sodium alginate has been widely used in the industry of food [1] and medicine [2]. However, the extraction process of sodium alginate still has many unconquerable defects, such as poor quality, high cost and easy degradation. In order to improve the quality and yield of sodium alginate. More and more production process are begun to research.

At present, there are several common extraction methods of sodium alginate at home and abroad, such as the method of acid coagulationacidification, the method of calcium coagulationacidification, the method of calcium coagulation-ion exchange, the method of enzyme rib, the method of ultrafiltration and the method of ultrasonic microwave co-processing. The precipitation rate of the method of acid coagulation-acidification is relatively slow, and it takes about 1-2 days to fully precipitate, and the precipitation particles are small [3], and the extraction process of acid coagulation-acidification is complex, the purity of product is low, so the method is not recommended as a process achieving mass production of sodium alginate. The method of calcium coagulation- acidification has some advantages, such as short time of consumption, large coagulation and easy separation [4]. But the extraction rate of sodium alginate is still lower, the purity of product is still lower, and the product is easy degraded and has other shortcomings.

Compared with the above two methods, the method of calcium coagulation-ion exchange has some advantages, for example, the rate of precipitation is fast, the time of extraction is less, and the step of adding a lot of dilute acid is avoided, which can minimize the degradation of products and improve the purity of products. However, the sodium carbonate solution which added in the digestion process in this method must be completely removed, otherwise it will react with the calcium chloride solution which added in the process of calcination to form an insoluble calcium carbonate solution, which will be mixed with sodium alginate [5]. Cellulase was added to kelp to obtain sodium alginate, this method is named enzymatic method. This method can greatly increase the dissolution of sodium alginate. However, most of the reasons why enzymatic hydrolysis has not been popularized in industrial production are that this method has high cost, high resource consumption and high requirements for technical content [6]. Therefore, it is extremely important to study a production process with high efficiency and low cost. Ultrafiltration method 
uses cellulose acetate membrane to intercept molecules with a relative molecular mass of 3000 [7], but the reaction process also goes through the steps of acid coagulation and acidification, so it is also possible to make sodium alginate acidic degrade.

Thus it can be seen there are all sorts of shortcomings to extract sodium alginate in the general approach. Based on efficient, low cost production mode to explore the optimal conditions of extraction process about sodium alginate, this experiment mainly adopts the coagulation-calcium ion exchange process to extract sodium alginate in kelp. By single factor experiment and orthogonal experiment, the concentration of $\mathrm{Na}_{2} \mathrm{CO}_{3}$, the time of digestion, the temperature of digestion in calcium-ion exchange process were explored, and the highest extraction yield about sodium alginate under which condition was explored.

\section{MATERIALS \\ Experimental Sample}

Kelp which bought in the supermarket.

\section{Reagents}

Methanal, anhydrous ethanol, hydrochloric acid, sodium carbonate, sodium chloride and calcium chloride which were all analytically pure and purchased from Damao chemical reagent factory in Tianjin.

\section{Intruments}

Electronic analytical balance (ALC-310.3), which purchased from Shanghai precision scientific instrument co., LTD. Concentrated type constant temperature heating magnetic stirrer (DF-101S), which purchased from gongyi yuhua instrument co., LTD. IR spectroscopy meter (T6), which purchased from Beijing general instrument co., LTD. Circulating water type multipurpose vacuum pump (SHB-A), which purchased from zhengzhou Great Wall industry \&trade co., LTD. Digital rotary viscometer (NDJ-1), which purchased from gao zhi precision instrument co. LTD in Shanghai.

\section{The Method and Content of Experiment The Pretreatment of Sample}

The kelp which bought in the supermarket, was washed and soaked firstly, the kelp was minced and digested secondly, and it was filtered and refrigerated for use at last.

\section{The Points of Operation}

The sample was coloured firstly. Kelp (1.0 g) was taken into a beaker, formaldehyde $(25.0 \mathrm{~mL}, 25 \%)$ was added, and then soaked for $24 \mathrm{~h}$ at room temperature. Formaldehyde can play a role of color fixation, fixing the pigment in kelp into the epidermal cells of kelp, and at the same time the cell wall was destroyed and accelerated the dissolution of sodium alginate. The sample was digested secondly. After filtration, solution $(50.0 \mathrm{ml})$ of sodium carbonate was added to the residue which filtered to soak for digestion. After digested, water $(50.0 \mathrm{ml})$ was added to dissolve, and the solution was adjusted to $\mathrm{pH}=7-9$ then. The sample was separated out thirdly. The above solution was filtered, solution of $\mathrm{CaCl}_{2}(50.0 \mathrm{ml}, 10 \%)$ was added to the filtrate, and then the water-soluble sodium alginate turned into large flocculent precipitate of insoluble calcium alginate. The sample was decalcified by exchange of ion fourth. The above precipitate was added solution of sodium chloride (15\%) for ion exchange. Large flocculent precipitate was converted into smaller precipitate, and It took 2-3 h to achieve the whole ion exchange approximately. The sample was precipitated by alcohol lastly. After filtrating by ion exchange, anhydrous ethanol was added to the filtrate, and sodium of alginate which partially dissolved in water was precipitated from the water to reduce the loss of sodium alginate.

\section{The Test of Single Factor}

The factors were investigated which affected the extraction rate of sodium alginate by calcium-ion exchange method, such as the concentration of $\mathrm{Na}_{2} \mathrm{CO}_{3}$, the time of digestion and the temperature of digestion.

\section{The test of orthogonal factor}

In order to make the experimental data more accurate and convincing, not only the single factor experiment but also the orthogonal experiment was designed to optimize the process of extraction. Orthogonal table $\mathrm{L} 16\left(4^{3}\right)$ was selected for the experiment, and the extraction rate was taken as the investigation target [8], and the horizontal table of orthogonal factors was set.

Table-1: The level of orthogonal factor

\begin{tabular}{|l|l|l|l|}
\hline Number & The concentration of $\mathbf{N a}_{2} \mathbf{C O}_{3}$ & The temperature of extraction & The time of extraction \\
\hline 1 & $2 \%$ & $30^{\circ} \mathrm{C}$ & $1 \mathrm{~h}$ \\
\hline 2 & $4 \%$ & $40^{\circ} \mathrm{C}$ & $2 \mathrm{~h}$ \\
\hline 3 & $6 \%$ & $50^{\circ} \mathrm{C}$ & $3 \mathrm{~h}$ \\
\hline 4 & $8 \%$ & $60^{\circ} \mathrm{C}$ & $4 \mathrm{~h}$ \\
\hline
\end{tabular}




\section{RESULTS AND ANALYSIS}

\section{The test of single factor}

\section{The influence of $\mathrm{Na}_{2} \mathrm{CO}_{3}$ concentration}

The solution of $\mathrm{Na}_{2} \mathrm{CO}_{3}(2,4,6,8 \%)$ was used for digestion. Sodium alginate was extracted at the digestion time of $3 \mathrm{~h}$ and the digestion temperature of $50^{\circ} \mathrm{C}$, the effect of different concentrations were explored on the extraction rate of sodium alginate.

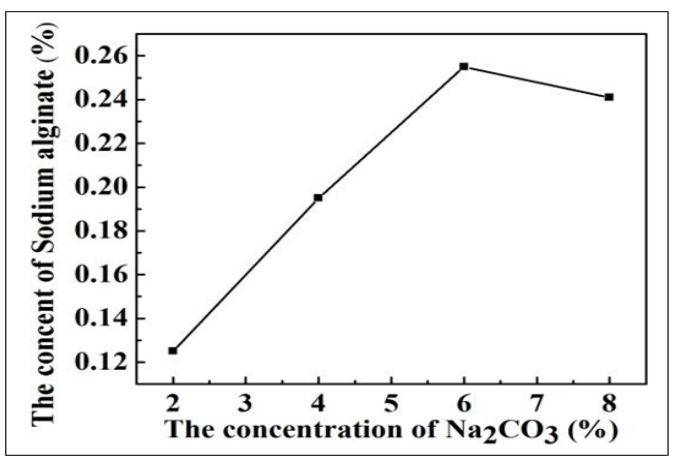

Fig-1: The effect of $\mathrm{Na}_{2} \mathrm{CO}_{3}$ concentration on the extraction amount of sodium alginate

As shown in Figure-1, as the concentration of $\mathrm{Na}_{2} \mathrm{CO}_{3}$ increased, the extraction amount of sodium alginate also increased and began to decrease after reaching the peak. It can be roughly estimated from Figure-1 that when the concentration of $\mathrm{Na}_{2} \mathrm{CO}_{3}$ is $6 \%$, the extraction amount of sodium alginate is about $25 \%$, which is the highest content.

The extraction amount of sodium alginate increased first, reached the peak, and then decreased. The main reason for this was that when the concentration of $\mathrm{Na}_{2} \mathrm{CO}_{3}$ was too low, sodium alginate in epidermal cells was not completely dissolved, so the extraction amount was low. After the increase of $\mathrm{Na}_{2} \mathrm{CO}_{3}$, the large alginate gel molecules were gradually decomposed into small molecules, so the extraction amount was also decreased relatively.

\section{The Effect of Digestion Time}

The digestion time $(1,2,3,4 \mathrm{~h})$ was illustrated respectively. At the concentration of $4 \%$ and the digestion temperature of $50^{\circ} \mathrm{C}$, the effects of different digestion times were investigated on the extraction rate of sodium alginate.

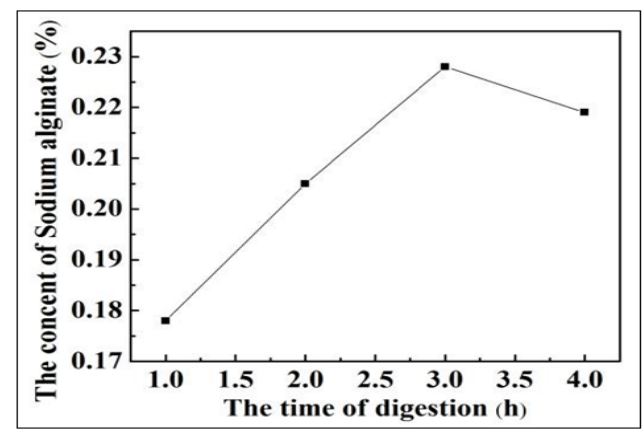

Fig-2: The effect of digestion time on the extraction amount of sodium alginate
As can be seen from Figure-2, with the increase of digestion time, the extraction amount of sodium alginate also increases, and the overall trend is to increase first and then decrease. It is roughly estimated from the figure that when the digestion time is about $3 \mathrm{~h}$, the extraction amount of sodium alginate is the largest.

There is a linear relationship between the extraction amount and the digestion time, the digestion time is too short and the kelp digestion is not complete, but the prolonged digestion time will lead to the fracture of large molecules in alginate into small molecules, reducing the extraction amount. Therefore, proper digestion time can increase the extraction amount of sodium alginate.

\section{The effect of digestion temperature}

The effects of different digestion temperatures were investigated on the extraction rate of sodium alginate, when the concentration was $4 \%$, and the digestion time was $3 \mathrm{~h}$. the digestion temperature (20, 40,50 and $60^{\circ} \mathrm{C}$ ) were investigated.

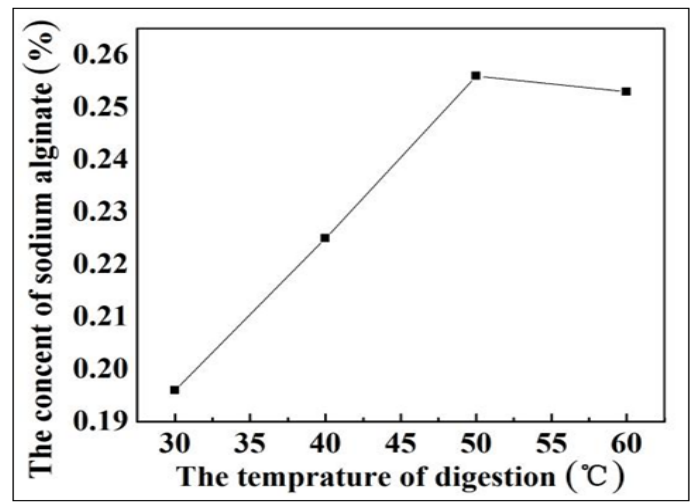

Fig-3: The effect of digestion temperature on the extraction amount of sodium alginate

As can be seen from Figure-3, the extraction amount of sodium alginate increased with the increase of digestion temperature, and began to decrease after reaching the peak. It can be roughly estimated from the figure that when the digestion temperature reaches about $50^{\circ} \mathrm{C}$, the extraction amount of sodium alginate reaches the peak. The extraction amount of sodium alginate does not increase with the increase of temperature.

The main reason for this trend is that the extraction amount is determined by the movement rate of the molecules, the higher the temperature, the faster the molecules move, the chemical reaction is accelerated, most of the kelp is digested, leading to the increase of the extraction amount. If the temperature continues to rise, the molecular motion rate will not continue to change when the temperature reaches a certain limit. However, when the temperature is too high, the large molecules of sodium alginate will break and split into small molecular fragments, which will 
lead to the decrease of the extraction amount of sodium alginate.

\section{The Test of Orthogonal Factor}

The orthogonal test table was set up according to the factors and levels of the test [9]. After the orthogonal experiment was carried out on the test data processing and analysis of variance, the factors which affected the extraction yield of sodium alginate were achieved from the orthogonal experiment. As can be seen from Table-2, the order of the influencing factors is: $\mathrm{A}>\mathrm{B}>\mathrm{C}$. As can be seen from Table-3, when the concentration ratio of $\mathrm{Na}_{2} \mathrm{CO}_{3}(\mathrm{~F})$ and the critical value $F$ compared, we found that $\mathrm{Na}_{2} \mathrm{CO}_{3}$ concentration is significantly influenced on investigation target [10], and therefore the main factors influencing the extraction yield of $\mathrm{Na}_{2} \mathrm{CO}_{3}$ concentration. Therefore, it can be determined that the optimal test conditions of this experiment are $\mathrm{A}_{3} \mathrm{C}_{3} \mathrm{~B}_{3}$, when the concentration of $\mathrm{Na}_{2} \mathrm{CO}_{3}$ is $6 \%$, the digestion time is $3 \mathrm{~h}$, and the digestion temperature is $50^{\circ} \mathrm{C}$, the extraction rate of sodium alginate is the highest.

Table-2: The table $L_{16}\left(4^{3}\right)$ of orthogonal test

\begin{tabular}{|l|l|l|l|l|l|}
\hline Number & A & B & C & D & The extraction rate of sodium alginate (\%) \\
\hline 1 & 1 & 1 & 1 & 1 & 8.23 \\
\hline 2 & 1 & 2 & 2 & 4 & 11.19 \\
\hline 3 & 1 & 3 & 3 & 2 & 14.26 \\
\hline 4 & 1 & 4 & 4 & 3 & 15.22 \\
\hline 5 & 2 & 1 & 2 & 3 & 13.75 \\
\hline 6 & 2 & 2 & 1 & 2 & 14.00 \\
\hline 7 & 2 & 3 & 4 & 4 & 21.58 \\
\hline 8 & 2 & 4 & 3 & 1 & 25.41 \\
\hline 9 & 3 & 1 & 3 & 4 & 21.52 \\
\hline 10 & 3 & 2 & 4 & 1 & 21.52 \\
\hline 11 & 3 & 3 & 1 & 3 & 19.42 \\
\hline 12 & 3 & 4 & 2 & 2 & 20.32 \\
\hline 13 & 4 & 1 & 4 & 2 & 15.39 \\
\hline 14 & 4 & 2 & 3 & 3 & 21.12 \\
\hline 15 & 4 & 3 & 2 & 1 & 19.65 \\
\hline 16 & 4 & 4 & 1 & 4 & 16.03 \\
\hline K1 & 48.9 & 58.89 & 57.68 & 74.81 & \\
\hline K2 & 74.74 & 67.83 & 64.91 & 63.97 & \\
\hline K3 & 82.78 & 74.91 & 82.31 & 69.51 & \\
\hline K4 & 72.19 & 73.71 & 73.71 & 70.32 & \\
\hline k1 & 12.225 & 14.7225 & 14.42 & 18.7025 & \\
\hline k2 & 18.685 & 16.9575 & 16.2275 & 15.9925 & \\
\hline k3 & 20.695 & 18.7275 & 20.5775 & 17.3775 & \\
\hline k4 & 18.0475 & 18.4275 & 18.4275 & 17.58 & \\
\hline R & 8.47 & 4.005 & 6.1575 & 2.71 & \\
\hline & & & &
\end{tabular}

Table-3: The variance analysis of orthogonal test

\begin{tabular}{|l|l|l|l|l|l|}
\hline Source of error & $\begin{array}{l}\text { Deviation sum } \\
\text { of squares }\end{array}$ & $\begin{array}{l}\text { Degree of } \\
\text { freedom }\end{array}$ & $\begin{array}{l}\text { The ratio } \\
\text { of } \mathbf{F}\end{array}$ & $\begin{array}{l}\text { Critical } \\
\text { value of F }\end{array}$ & Conspicuousness \\
\hline $\begin{array}{l}\text { the concentration of } \\
\mathrm{Na}_{2} \mathrm{CO}_{3}\end{array}$ & 635.32 & 3 & 10.7 & 9.28 & Significant \\
\hline $\begin{array}{l}\text { The temperature of } \\
\text { digestion }\end{array}$ & 160.58 & 3 & 2.71 & 9.28 & No significant \\
\hline The time of digestion & 343.23 & 3 & 5.78 & 9.28 & No significant \\
\hline Blank of column & 59.36 & 3 & & & \\
\hline The error & 1198.49 & 12 & & & \\
\hline
\end{tabular}

\section{The analysis of Infrared Spectroscopy}

In order to investigate the structure of the extracted sample further, the product was tested by infrared spectroscopy. 


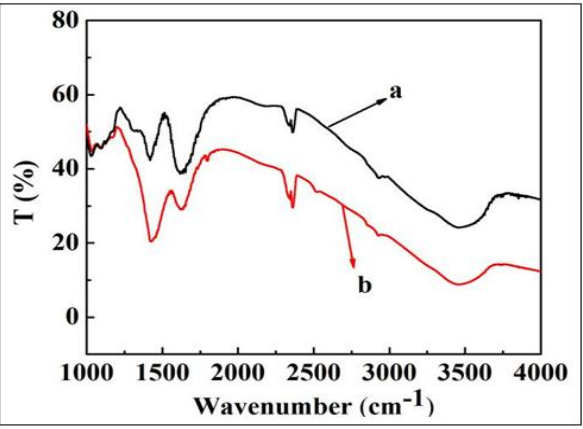

Fig-4: The Infrared spectra of sterling sodium alginate (a) and sodium alginate sample (b)

As shown in Figure-4, the line of (a) is the Infrared spectra of sterling sodium alginate and the line of (b) is the Infrared spectra of sodium alginate sample. By comparing $b$ with $a$, it can be seen that the spectra of (a) and (b) were identical, so the purity of the sodium alginate sample which be extracted from the kelp was very high. The stretching vibration absorption peak of hydroxyl groups is at $3470 \mathrm{~cm}^{-1}$, the stretching vibration absorption peak of C-H is at $2930 \mathrm{~cm}^{-1}$, the stretching vibration absorption peak of carbonyl group is at 1730 $\mathrm{cm}^{-1}$, the stretching vibration absorption peak of $\mathrm{C}-\mathrm{O}$ is at $1220 \mathrm{~cm}^{-1}$. It can be seen there are all peeks of sodium alginate in the curve of $b$ in Figure-4. So it can conclude that the extraction contains functional groups which have the corresponding peak with sodium alginate. However, some impurity peaks appear in the infrared spectrum to be the stretching absorption vibration peaks of impurities generated in the extraction process of sodium alginate [11].

\section{The analysis of the viscosity}

The viscosity of sodium alginate is one of the important criteria for the quality evaluation of sodium alginate, the higher of the viscosity, the better of the quality, the poor quality, conversely. In order to investigate the quality of the extracted sample further, the product was tested by viscosity of sodium alginate. According to the determination method of GB 1886.243 2016 [12], the viscosity of sodium alginate was determined in this experiment, it tested that the viscosity of the sodium alginate solution is $131 \mathrm{~Pa} \mathrm{~s}^{-}$ ${ }^{1}\left(20^{\circ} \mathrm{C}\right)$, It is lower than the viscosity of national standard of food $\left(150 \mathrm{~Pa} \mathrm{~s}^{-1}, 20^{\circ} \mathrm{C}\right)$ relatively. Because there are difference condition between laboratory and industrial production, it can not be added into the food, but can be added to industrial supplies as an additive.

\section{CONCLUSION}

In this paper, calcium coagulation-ion exchange process was applied to extract the sodium alginate from the kelp, it is obtained from the analysis of the data, that the factors which affected the extraction yield of sodium alginate was the concentration of $\mathrm{Na}_{2} \mathrm{CO}_{3}>$ the temperature of digestion $>$ the time of digestion. When the concentration of $\mathrm{Na}_{2} \mathrm{CO}_{3}$ was $6 \%$, the time of digestion was $3 \mathrm{~h}$, and the temperature of digestion was $50^{\circ} \mathrm{C}$, the extraction rate of sodium alginate was the highest, and the extraction rate of sodium alginate was $25.79 \%$. At the same time, The product of sodium alginate which obtained in this experiment was detected by Infrared spectroscopy, and the resulting product is confirmed to be sodium alginate, the sodium alginate was obtained which can be added to industrial supplies as an additive.

\section{REFERENCES}

1. Xiaoxue Y. Study on the comprehensive extraction and purification technology of polysaccharide in kelp [D]. Shandong agricultural university, 2017.

2. Yu L. Sodium alginate and its fiber were extracted by biological enzyme [D]. Dalian university of technology, 2013.

3. Yonggang P, Yongsheng Z, Junling J. Study on the preparation and properties of microcapsule which was extracted from sodium alginatechitosan-honeysuckle [J]. Printing and dyeing auxiliaries, 2015, 32(12): 15-18.

4. Panli H, Xiaojun S, Jinghuan C. Advances in extraction and functional modification of sodium alginate [J]. Chemistry and industry of forest products, 2017, 37(4): 13-22.

5. Liangliang X, Chen Y, Xiaoya W. Preparation and characterization of sodium alginate chromotropic microspheres [J]. Chemistry teaching, 2018(1):7981.

6. Maodong P, Jiacheng L, Xianghui W. Extraction technology and characterization of sodium alginate from sargassum from Hainan[J]. Resource development and marketing, 2009, 25(8): 673-675.

7. Razumov AN, Bobrovnitsky IP, Mikhailov VI, Kudryavtsev ON. Manufacturing gel techniques. use for a dietary and treatment-and-prophylactic food [D]. Publishing House, Moscow, 2004.

8. Yanxian S, Yutao M, Qin Z. Optimization of extraction and purification of sodium alginate from kelp [J]. Food science and technology, 2015, (6): 289-293.

9. Hongyun T, Hongxin W, Yixing D. Study on ultrasonic-microwave assisted extraction of sodium alginate [J]. Journal of food and biotechnology, 2012, 31(02): 217-223.

10. Qiuping Y, Xiaolan Z. Study on a new extraction process of sodium alginate [J]. Food research and development, 2005, (5): 100-102.

11. Xiao L, Chao G, Ying W. Study on the technology of extracting sodium alginate from millet by complex enzymatic method [J]. China agricultural science and technology guide, 2019, 21(2):98-103.

12. Weiyan Q, Ziming Yang, S. Advances in the extraction of sodium alginate [J]. Shandong chemical industry, 2018, 47(19):56-59. 